\title{
The dependence of dispersion powder obtained from select high speed way, the grinding tools and different materials
}

\author{
Y.V. Titov ${ }^{\dagger}$, D.S. Rechenko, N.V. Khmarina, A.V. Nikitina \\ †tyrin-88@mail.ru
}

Omsk State Technical University, pr. Mira 11, 644050 Omsk, Russia

\begin{abstract}
This work was designed to study the grinding of various solid, multi-component materials by mechanical means, without significantly altering the original physical and mechanical properties. Introduced high-speed method of producing a powder is universal and the only one in its class, is to obtain a powder of different magnetic materials. Preparation of the powder into the protected against oxidation environment is also a new method to obtain powders by mechanical means. The article is devoted to research on the identification of the resulting dispersion, depending on the installation of high-speed powder by grinding disc. Dispersible powders obtained at different processing speeds were measured with an electron microscope. According to the research produced a graph that allows you to receive the necessary powder dispersion by changing the speed of rotation of the grinding disc. The possibility of producing ultra high-speed method of powders with a particle size does not exceed the declared value. The study of the mechanical method of producing ultrafine powders. Defined dispersity obtained powder of different materials. The dependence of the dispersion of the powder obtained from the selection of abrasive tools on Bakelite and metal bond. The most important application of the method presented high obtain various powders is in research, namely, for small batch powder from absolutely any solid multi-component material, it is sufficient for only about 100 grams of the starting material. Using powders produced high-speed method of magnetic materials can be used in the creation of so-called "magnitoelastikov". It can also be applied in various modifiers to be added to the alloys in foundries.
\end{abstract}

Keywords: nano and ultra-disperse powder, grinding work, high-speed way, abrasive wheel, abrasives, liquid nitrogen.

\section{Зависимость дисперсности получаемого порошка высокоскоростным способом от выбора шлифовального инструмента и различных материалов}

\author{
Титов Ю.В. ${ }^{\dagger}$ Реченко Д.С., Хмарина Н.В., Никитина А.В. \\ †tyrin-88@mail.ru
}

Омский Государственный Технический Университет, Пр. Мира, д. 11, 644050 Омск, Россия

Данная работа была направлена на изучение измельчения различных твердых, многокомпонентных материалов механическим способом, без значительного изменения изначальных физико-механических свойств. Представленный высокоскоростной способ получения порошка - является универсальным и единственным, в своем классе, именно для получения порошка из различных магнитных материалов. Получение порошка в защищенной от окисления среде, так же является новым, в методике получения порошков механическим способом. Статья посвящена исследованиям по выявлению зависимости дисперсности получаемого на высокоскоростной установке порошка от скорости вращения мелющего диска. Дисперсность порошка, полученного при различных скоростях обработки, измеряли на электронном микроскопе. По результатам исследований получен график зависимости, позволяющий получать порошок необходимой дисперсности при помощи изменения скорости вращения мелющего диска. Показана возможность получения ультрадисперсных порошков высокоскоростным способом, размеры частиц которого не превышают заявленных значений. Проведено исследование механического метода получения ультрадисперсных порошков. Определена дисперсность получаемого порошка различных материалов. Выявлена зависимость дисперсности получаемого порошка от выбора абразивного инструмента на бакелитовой и металлической связках. Наиболее важное применение представленного высокоскоростного способа получения различных порошков заключается в научных исследованиях, а именно: для получения небольшой партии порошка, из абсолютно любого твердого мно- 
гокомпонентного материала, достаточно всего лишь около 100 граммов исходного материала. Использование порошков, полученных высокоскоростным способом, из магнитных материалов может найти применение в создании, так называемых «магнитоэластиков». Так же возможно применение в различных модификаторов, для добавления их в сплавы в литейном производстве.

Ключевые слова: нано и ультрадисперсные порошки, высокоскоростной способ, механический метод, шлифовальный круг, жидкий азот.

В настоящее время ключевым фактором развития экономики и обороноспособности государства является разработка новых материалов, их обработка и применение. Актуальным направлением развития современной науки является получение нано и ультрадисперсных порошков различных металлов и исследование их свойств. Из-за сверхмалых размеров частиц порошкам присущи уникальные сочетания химических, электрических, магнитных, радиопоглощающих, механических и других свойств, определяющих новые функциональные, конструкционные и эксплуатационные характеристики. Структура порошков оказывает существенное влияние на свойства и зависит от методов их получения [1]. К методам предъявляют следующие требования:

1) высокая скорость образования центров зарождения частиц и малая скорость их роста;

2) обеспечение временной стабильности частиц, защита их поверхности от самопроизвольного окисления и спекания в процессе изготовления;

3) получение частиц или зерен заданного размера;

4) высокая производительность и экономичность;

5) контроль над параметрами [2,3].

Методы получения нано и ультрадисперсных материалов делятся на физические, химические, биологические и механические.

Основными методами механического измельчения являются дробление и размол твердых материалов, диспергирование расплава, обработка твердых (компактных) материалов резанием. Механические методы основаны на воздействии больших деформирующих нагрузок: трения, давления, прессования, вибрации, кавитационных процессов и т. п. [4].

Для механического измельчения твердых тел применяются мельницы различного типа: планетарные, шаровые, струйные, вихревые, вибрационные и другие. В связи с тем, что при получении нано и ультрадисперсных порошков работа измельчения пропорциональна площади образующейся поверхности, необходимо использование мельниц высокой мощности [2].

Важными достоинствами использования механического метода измельчения (мельница) являются:

1) получение нано и ультрадисперсных порошков из многокомпонентных сплавов за один этап;

2) возможность измельчать различные материалы и получать порошки сплавов в большом количестве;

3) сравнительная простота технологии.

Недостатки механического метода:

1) разброс размеров и многообразие форм частиц;

2) сложность регулирования состава продукта в процессе измельчения;

3) чем сложнее компонент и точнее критерий ка- чества, тем сложнее управлять структурой металла, и тем выше стоимость производства;

4) возможность загрязнения нано и ультрадисперсных порошков продуктами истирания мелющих тел или рабочих органов мельниц $[5,6]$.

Механический метод является перспективным для создания нано и ультрадисперсных порошков из многокомпонентных сплавов, однако для более эффективного его использования полезны знания о физических процессах, происходящих во время механических воздействий $[7,8]$. Поэтому необходимо выяснение возможностей высокоскоростного способа и экспериментальное исследование процессов, протекающих в твердых телах при изготовлении порошков [9]. Применяемая в эксперименте установка представляет собой мельницу.

Обработка материала осуществлялась при окружной скорости мелющего диска до 300 м/с при одновременном вращательном и возвратно-поступательном движении заготовки. В качестве мелющего диска использовался шлифовальный круг с абразивными элементами (абразивными головками диаметром 12 мм). Подача заготовки осуществлялась порядка 1 мм/мин с одновременной подачей жидкого азота из криогенного резервуара через термошланг в зону обработки около 1 л/мин. Размеры частиц порошка регулировались окружной скоростью мелющего диска, выбором абразивных головок и подачей заготовки [10].

Заготовка, установленная соосно одной из абразивных головок в зажимном устройстве, приводилась во вращение. После достижения мелющим диском заданной скорости вращения, заготовку непрерывно охлаждали жидким азотом в течение всего процесса истирания. Шлифовальный круг подводили к заготовке до обеспечения контакта, в результате чего происходило измельчение заготовки истиранием. Порошок извлекали из помольной камеры, используя воздуходувный улавливатель частиц, соединенный с устройством для сбора измельченного материала. После истирания заготовки устройство отключали, измельченный материал удаляли из устройства сбора, устанавливали новую заготовку (рис.1) [11].

Эксперименты проводились с материалами, имеющими различную твердость, хрупкость, ударную вязкость (рис. 2) [12,13].

Полученные порошки имели размер частиц в диапазоне от 100 нм до 1,5 мкм (рис. 3). Средний размер частиц порошка из стали ВК8 составил 1100 нм, из быстрорежущей стали Р18-950 нм, из латуни - 400 нм, из ферромагнетика - 280 нм. Лучшие результаты получились у порошков из алюминия и неодимового магнита (рис. 3c). 
В ходе экспериментов были использованы абразивные элементы на бакелитовой и металлической связках.

Из полученных данных следует, что разброс по дисперсности уменьшается с уменьшением диапазона зернистости абразивных элементов (рис. 4).

Механический метод обработки с использованием шлифовального круга обеспечивает безотходную обработку заготовки, уменышение разброса размеров и возможность получения частиц менее 0,1 мм. Добавление жидкого азота уменьшает вероятность возникновения высоких температур, возникающих при истирании на высоких ско-

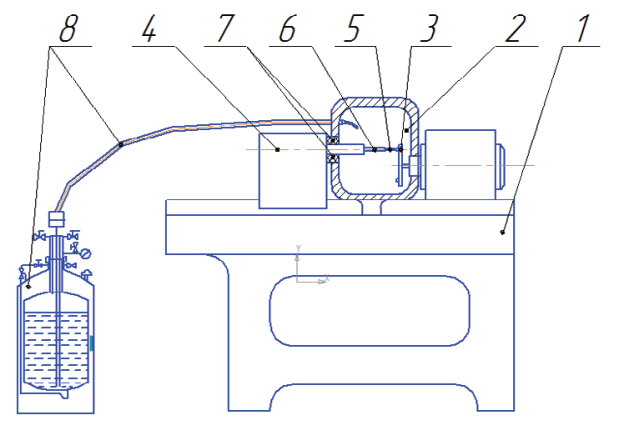

Рис. 1. Схема установки 1 - рама; 2 - герметичная камера; 3 шлифовальный круг; 4 - устройство подачи; 5 - заготовка; 6 - оправка; 7 - герметичные элементы; 8 - устройство подачи жидкого азота в зону обработки.

Fig. 1. Installation scheme 1 - bed, 2 - airtight enclosure, 3-abrasive wheel, 4-work feeder, 5-work piece, 6- mandrel body, 7- airproof cell, 8- coolant transfer device of liquid nitrogen in the treatment area (cutting region). ростях, следовательно, снижается пожароопасность в ходе работы $[14,15,16]$.

Выявление зависимости дисперсности полученного порошка от материала, из которого он был получен, а так же от выбора абразивного инструмента - несомненно, важно. Более важным будет выявление зависимости влияния различных свойств материала на дисперсность полученного порошка для понимания основ и принципавысокоскоростного скалывания частиц из различного получаемого материала абразивными элементами. Так же необходимо исследовать свойства полученного порошка из магнитного

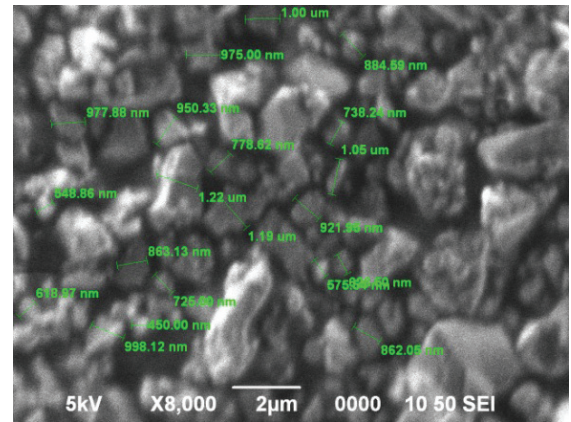

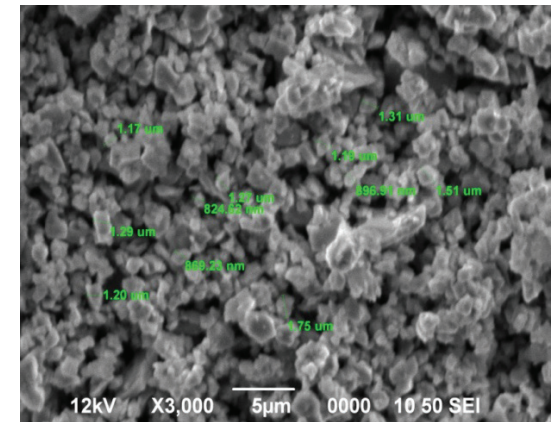

b

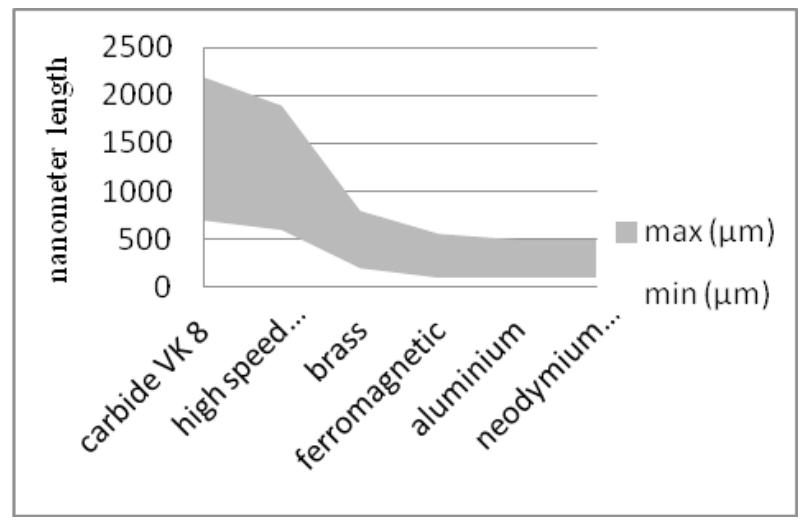

Рис. 2. Дисперсность полученного порошка из различных материалов.

Fig. 2. The dispersion of the obtained alloy powder of variety of materials.

Рис. 3. Дисперсность полученного порошка сплава P18 (a), сплава ВК8 (b), неодимового магнита (c).

Fig. 3. The dispersion of the obtained alloy powder high speed steel R18(a), carbide VK8(b).

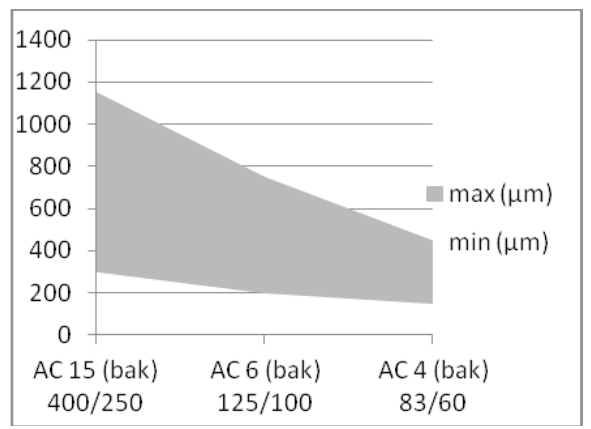

a

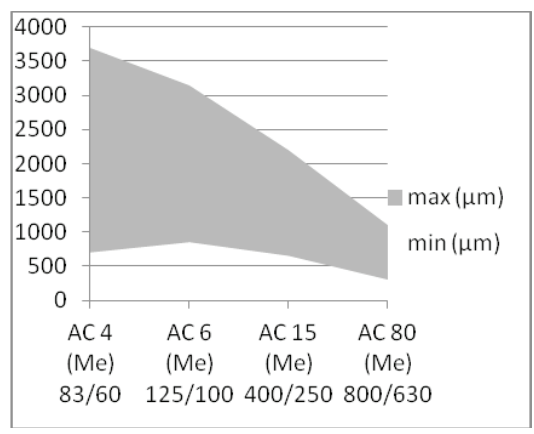

$\mathrm{b}$

Рис. 4. Зависимость дисперсности получаемого порошка от выбора абразивного инструмента на бакелитовой связке (а) на металлической связке (b).

Fig. 4. The dependence of the dispersion of the powder obtained by the choice of grinding tool on bakelite bond (a) and metal bond (b). 
материала на рентгеновском аппарате, для определения его магнитных свойств, в сравнении с исходным материалом.

Благодарность. Данная работа выполнена при финансовой поддержке Министерства образования и науки РФ.

Acknowledgements. Financial support of Ministry of Education and Science is gratefully acknowledged.

\section{Литература / References}

1. A. Izgorodin. Nanoindustry and training. A. Izgorodin, G. Chistoborodov; "In the world of hardware." 5 (80). 2008. [А. Изгородин. Наноиндустрия и подготовка специалистов. А. Изгородин, Г. Чистобородов; «В мире оборудования». 5 (80). 2008.]

2. B. M. Balayan, A. G. Kolmakov, M. I. Crimson A. M. Moles. Nanomaterials. Classification, characteristics of properties, application and production technology. Moscow, 2007. 125 p. [Б. М. Балоян, А.Г. Колмаков, М.И. Алымов, А.М. Кротов. Наноматериалы. Классификация, особенности свойств, применение и технологии получения. Москва, 2007. 125 с.]

3. R. Hanninka, A. Hill. Nanostructured materials. Moscow: Technosphere, 2009. 488 р. [Р. Ханнинка, А. Хилл. Наноструктурные материалы. Москва: Техносфера, 2009. 488 c.]

4. S.S. Kiparisov, G.A. Libenson. Powder metallurgy. M.: Metallurgy, 1991, 432 p. http://www.twirpx. com/file/403354/

5. D.I. Ryzhonkov, V.V. Levina, E.L. Dzidziguri. Nanomaterials: a tutorial. 2 Ed. M.: BINOM. Knowledge Laboratory, 2010. 365 р. [Д. И. Рыжонков, В. В. Лёвина, Э. Л. Дзидзигури. Наноматериалы: учебное пособие. -2 е изд. М.:БИНОМ. Лаборатория знаний, 2010. 365 c.]

6. S. V. Matrenin, B. B. Ovechkin. Nanostructured materials in mechanical engineering: a tutorial/Tomsk Polytechnic University. Tomsk: Publishing house of Tomsk Polytechnic University, 2009. 186 p. [С.В. Матренин, Б. Б. Овечкин. Наноструктурные материалы в машиностроении: учебное пособие/Томский политехнический университет. Томск: Изд-во Томского политехнического университета, 2009. 186 с.]

7. Yu. N. Polyanchikov, A.G. Shirtladze, A. N. Vorontsova (et al.). Nanotechnology in Engineering: a tutorial. Stary Oskol: TNT, 2012. 92 p. [Ю.Н. Полянчиков, А.Г. Схиртладзе, А.Н. Воронцова (и др.). Нанотехнологии в машиностроении: учебное пособие. Старый Оскол: ТНТ, 2012. 92 с.]

8. A.N. Kovshov, Yu.F. Nazarov, I.M. Ibragimov. Nanotechnology-based technique: Proc. Guide for students. Executive. Proc. institutions. M.: Publishing Center «Academy», 2009. 240 p. [А.Н. Ковшов, Ю. Ф. Назаров, И. М. Ибрагимов. Основы нанотехнологии в технике: учеб. пособие для студ. высш. учеб. заведений. М.: Издательский центр «Академия», 2009. 240 c.]

9. M. I. Lerner, V. I. Davidovich, N. V. Svarovskaya. Physical Mesomechanics. 7 (2), 340-343 (2004). (In Russian) [М.И. Лернер, В.И. Давыдович, Н. В. Сваровская Физическая мезомеханика. 7 (2), 340 - 343 (2004)].

10. Patent 146455 Russian Federation, IPC B22F 9/04. The apparatus for producing metal powders./AY Popov, DS Rechenko, Y. Titov, K. K. Gosina, RW stones; Omsk State. Tech. Univ. № 2014119229/02; Appl. 05/13/14; Publ. 10.10.14. Bull. № 28. 3.: silt. 1 [Патент 146455 РФ, МПК B22F 9/04. Устройство для получения металлических порошков./А.Ю. Попов, Д.С. Реченко, Ю.В. Титов, К. К. Госина, Р.У. Каменов; Омский гос. Техн. Ун-т. №2014119229/02; Заявл. 13.05.14; Опубл. 10.10.14. Бюл. № 28.3 с.: ил. 1]

11. Patent 55665 RF, IPC B24D 17/00. Grinding wheel for rough and abrasive machining./DS Rechenko, YR Nurtdinov, AY Popov; Omsk State. Tech. Univ. №2006111080/22; Appl. 05.04.06; Publ. 27.08.06. Bull. №24. [Патент 55665 РФ, МПК В24D 17/00. Шлифовальный круг для алмазно-абразивной обработки./Д. С. Реченко, Ю.Р. Нуртдинов, А. Ю. Попов; Омский гос. Техн. Ун-т. №2006111080/22; Заявл. 05.04.06; Опубл. 27.08.06. Бюл. № 24.]

12. Powdermetallurgy.Materials, technology,properties, fields of application: Manual I. M. Fedorchenko, I. N. Franzevich, I.D. Radomyselsky etc.; Ans.Ed. I.M. Fedorchenko. Kiev Naukova Dumka, 1985. 624 p. [Порошковая металлургия. Материалы, технология, свойства, области применения: Справочник Федорченко И.М., Францевич И.Н., Радомысельский И.Д. и др.; Отв. ред. Федорченко И. М. Киев: Наук. думка, 1985. 624 с.]

13. L. T. Proskurovskaya. Physico-chemical properties of ultrafine aluminum powders electroexplosion: dis.... Cand. chem. Sciences. - Tomsk: TSU, 1988. 155 p. [Л. Т. Проскуровская. Физико-химические свойства электровзрывных ультрадисперсных порошков алюминия: дис. канд. хим. наук. Томск: ТГУ, 1988. 155 с.]

14. I. M. Fedorchenko, I. N. Franzevich, I. D. Radomyselsky. Powder metallurgy. Kiev: Naukova Dumka, 1985. 624 р. [Федорченко И.М., Францевич И.Н., Радомысельский И.Д. Порошковая металлургия. Киев: Наукова думка, 1985. 624 с.]

15. A. G. Kissel, D.S. Rechenko, A.Y. Popov, V.R. Titov. Nanotchnics 1 (37), 73 - 74 (2014). [А.Г. Кисель, Д. С. Реченко, А. Ю. Попов, В. Р. Титов. Нанотехника. 1 (37), $73-74(2014)]$.

16. D.S. Rechenko, A.G. Kissel, A.Y. Popov, A.V. Titov. Preparation soot ferromagnets an attritor with liquid nitrogen cooling./Omsk Univ OmSTU, 2013. S. 165 - 168. [Д. С. Реченко, А.Г. Кисель, А.Ю. Попов, А.В. Титов. Получение ультрадисперсного порошка ферромагнетиков на мельнице тонкого помола с охлаждением жидким азотом. / Омск: Изд-во ОмГТУ, 2013. C. 165 - 168.] 